\title{
Considering for Strengthening Construction of Rural Public Infrastructure Construction in Yanting_-By investigating of 9 towns, 41 countrysides
}

\author{
Yan Liu ${ }^{a}$, Hongan Xiao ${ }^{b}$ \\ College of Economics and Management, Sichuan Agricultural University, Chengdu, Sichuan, \\ 611130, China \\ a52962408@qq.com;
}

Keywords: Yanting, New Socialist Countryside, Public infrastructure , strategy

\begin{abstract}
The rural public infrastructure construction is one of the important contents in New Socia list Countryside Construction。Through investigating and analyzing the current situation and probl ems of rural public infrastructure construction in Yanting 9 towns, the article held that further devel oping the rural public infrastructure construction of Yanting should be set about the following four aspects: Increasing financial investment to establish long-effect management mechanism ;Suiting $\mathrm{m}$ easures to local conditions, and formulating to develop rural sustainable development planning ;Spe eding up the construction of agricultural mechanization to improve the level of farming mechanizati on; Strengthening construction of Ecological environment to better the village residential environm ent.
\end{abstract}

\section{Introduction}

The construction of a new socialist countryside is an inevitable requirement to comprehensively realize a well-off society and to build a harmonious socialist society. In 2006, Several Opinions of the State Council on Promoting the Construction of a New Socialist Countryside enacted by the central State Council put forward new rural construction requirements, which could be interpreted as "the development of production, affluent life, rural civilization, clean and tidy villages and democratic management". And with particular emphasis on the process of building a new socialist countryside, we must strengthen the construction of rural infrastructure and accelerate the development of rural social undertakings. The 17th Communist Party of China National Congress further proposed increasing investment in agriculture and speeding up the construction of rural infrastructure. The provincial party committee and government also issued a number of documents, which emphasized that rural infrastructure construction was a key node to guarantee the agricultural industry development, to improve the rural environment and to improve the life quality of farmers , as well as an important condition mattering the new socialist countryside construction

Rural infrastructure is the general term of public service facilities provided for the development of rural production and the assurance of the farmers' livelihood. To strengthen the infrastructure construction is to vigorously strengthen water conservancy construction, accelerate the construction of rural roads, solve the problems of rural energy and drinking water safety, actively develop the rural compulsory education and health services, etc. Yanting County is located in the southeast of Mianyang city, Sichuan, and there is about 600 thousand mu of arable land throughout the county. With the unique natural conditions and advantages of agricultural industrialization, Yanting becomes the key agricultural county of Mianyang in the field of overall urban-rural development. However, the relative lack of financial investment, underdeveloped infrastructure and other unfavorable factors become the bottlenecks in the process of Yanting's new rural construction. On the basis of investigating and analyzing the current situation and the main existing problems of Yanting's rural infrastructure, this article tries to come up with some feasible countermeasures, and intends to further quicken the process of new rural construction in Yanting. 


\section{The Development Status of Rural Infrastructure in Yanting}

Along with the research group in July 2012, the author made a field survey in Yanting County, Mianyang. A large quantity of first-hand information was collected. Data in this article are derived from this detailed investigation, involving a total of 41 villages which are distributed in 9 townships-Maogong, Lianghe, Xinnong, Julong, Mayang, Yulong, Huangxi, Huangdian and Yunxi, and covering an area of 141.15 square kilometers. The current situations of rural infrastructure are mainly divided into three parts, including the current situations of the agricultural production facilities, the peasants' production and living facilities and the rural public utilities facilities.

\section{The Current Situation of the Agricultural Production Facilities.}

1) Farmland Water Conservancy Facilities

Nine villages and towns are located in the northern central of the Sichuan Basin, the central areas of Yanting. Due to the distribution along the Zi Jiang River, its' water resources are relatively abundant.

2)Agricultural Machinery Facilities

The research results of agricultural machinery equipments in Yanting can be summarized as follows: 174 sets of tractors, 842 sets of cultivators, 119 sets of rice transplanters, 1,569 sets of pumping irrigation machines, 206 sets of water-saving irrigations, 60 sets of harvesters, 4,025 sets of threshers, 433 sets of motor-sprayers, and 189 units of trucks.

\section{The Current Situation of the Peasant's Production and Living Facilities .}

1) Road Traffic

Based on the provincial highway S101, the building Highway from Chengdu to Nanbu County, Nanchong, and the Highway from Mianyang to Xichong County, Nanchong, the arterial highway network in Yanting is formed. Otherwise, there are another 7 County Roads, 20 Township Roads, and 5 special lanes. Road traffic infrastructure among the nine townships is quite good, for which there are three provincial highways and four grade highways across the county.

2 )Rural Energy Resources

The government in Yanting attaches importance to the Rural Electric Network Construction and Transformation Project. With a relatively perfect electric power network and 65 existing substations, the power have thoroughly covered all the villages.

The Current Situation of the Rural Public Utilities Facilities.

1)Informatization Construction

2)Construction of Culture, Sports and Health-Care

3) Construction of Environmental Management Facilities

\section{Existent Main Problems in the Construction of Rural Public Infrastructure in Yanting}

Obsolescent Infrastructure, Lacking of Maintenance.According to the survey, the rural infrastructure construction projects are multiple and scattered: the management workload is heavy; The staff and organizations in these towns and villages are just temporary; And the work of the infrastructure management and maintenance is seriously scanty. Thereby, the phenomenon of aging rural infrastructure exists commonly, especially in irrigation and water conservancy facilities. In the nine investigated townships, the majority of the reservoirs are small and medium-sized as well as dangerous; The ability of effective irrigation is feeblish; Part of the canals are severely blocked because of landslide and disrepair for years; And even a lot of the pumping stations are so 
completely destroyed that can not be used anymore. In addition, the rural roads are both in poor quality, serious damage degree and the lack of lighting system. As the survey data shown, the total length of rural roads have reached 308.73 kilometers, including 110 kilometers long cement-bound macadam, 91.2 kilometers long hardening roads, and about one-third of muddy roads. Once it rains, it becomes difficult for vehicles and pedestrians to pass the muddy roads, whose surface were fully covered by seeper, leading to a serious traffic impediment for nearby villagers. The surface of the newly built cement-bound macadam and hardening roads in recent years also appeared some disrepairs. The reasons why damaged pavement and roadbed cave-in happened after a period of time could be explained as follows: on the one hand, the original construction standard was low; on the other hand, under the heavy burdens, road managements and maintenances were in extreme shortage. Nowadays, the "traffic within every village" was turned into "repair in every village", which reduce the functions and service life of rural roads.

The Lagging and Separating Infrastructure Planning. Considering that the construction of rural infrastructure is often involved in agriculture, forestry, water affairs, land, transportation, communication, electricity, construction of urban-rural planning, tourism, education, sports, health, and many other departments, the establishment of infrastructure planning is an extremely complex systematic engineering. At present, the agricultural funds are scattered in various departments of Yanting County, and all kinds of planning are made by each department alone. The lack of countylevel overall planning caused several problems. Firstly, many of the infrastructure projects were dissevered artificially, so that the connections within the projects were not good enough. Secondly, resources could not be effectively allocated. Thirdly, the phenomenon of repeated construction existed, so did the funds waste. Hunan Social Science, 2010, (04)], for example, the attempt of combining the rural infrastructure and environmental construction with the villages layout and construction has failed, resulting in the low utilization rates of both partial built roads and drinking water facilities, as well as the inefficiency of funds use. In each township, without the governmental unified planning and management, many villagers build, site and renovate their houses optionally, which lay hidden troubles in the village residential project in new rural construction in the future.

The Growth of Agricultural Economy Was Impeded By the Low Level of Agricultural Mechanization.The implementation of agricultural mechanization can greatly improve agricultural labor productivity and comprehensive production capacity, reduce the cost of agricultural production, improve the quality of agricultural products, and enhance the market competitiveness of agricultural products, it can be seen from the survey data that the rural agricultural mechanization level of Yanting only reached 31\%. The speed of agricultural mechanization development is too slow, which has become an important factor to impede the growth of farmers' income. The main reasons for the low level of agricultural mechanization can be decomposed into two aspects: Firstly, to a certain extent, the development of agricultural economy is impeded by the small quantity of agricultural machinery and the low level of agricultural production; Secondly, the structure of agricultural machine and equipment is irrational. The majority of farm implements are small, and only a few of them are in large and medium-sized. The structural contradiction of agricultural equipment is obvious. Power matching is relatively low. Agricultural machinery operation range is narrow. The agricultural labor productivity has been greatly lowered. Some of the vintage tractors and equipment with behindhand technology are still in use, causing too large energy consumptions, which is not conducive to environmental protection. There is a small amount of machinery in multipurposes or with a high efficiency of comprehensive utilization.

The Salient Dirty and Messy Phenomenon Caused By the Lack of Rural Environmental Governance.The comprehensive regulation of inhabited environment in these villages is a necessary means to achieve the improvement of rural living environment as well as one of the core contents of the construction of a new socialist countryside. In the new rural construction, the strategic objectives of rural infrastructure construction include the popularization of rural biogas and fast development in household equipment reformation project, by which to make biogas digester suitable for every possible house and improve rural ecological environment. in Yanting's rural status quo, because part of the villages don't have any sanitation facilities, sewages and the 
feces of human and animals in daily life are not timely collected and effectively treated. Villager's heap garbage everywhere and the drains are often blocked by scattered rubbish. Especially in summer, the stench of garbage can easily cause infectious diseases, seriously threatening the health of the nearby villagers. Due to the lack of effective government supervision, a lot of farmers wildly used pesticides and chemical fertilizers, along with discretionarily straw-burning behaviors in the process of agricultural production, resulting in the atmospheric pollution and agricultural soil pollution. In addition, the phenomenon of rural industrial pollution was very serious too, especially the emission of pollution sources such as "waste liquid, waste gas and waste residue" in rural individual enterprises along the Zi Jiang River were random.

\section{References}

[1] Wei-jia Zhong. Analysis of the Problems Existing in the Construction of Rural Infrastructure in Jiang-xi Province . Agricultural Economy, 2011, (04)

[2] Chun-ju Gao. Current Situation, Problems and Countermeasures for Construction of Rural Public Infrastructure Construction in Hengshui .Hubei Agricultural Sciences, 2010, (04)

[3] Shu-zhen LI. The Construction Analysis of County Infrastructure from the New Rural Perspective. Productivity Research, 2010, (06)

[4] Yu-jun Lu. Rural Infrastructure Construction and Reason Analysis of Existing Problems in Village Renovation . Agricultural Economy, 2011, (07) 